\title{
The Introduction of Tobacco Excise Taxation in the Gulf Cooperation Council Countries: A Step in the Right Direction of Advancing Public Health
}

\author{
Sofia Delipalla ( $\nabla$ sd@uom.edu.gr) \\ University of Macedonia \\ Konstantina Koronaiou \\ University of Macedonia \\ Jawad A. Al-Lawati \\ Ministry of Health \\ Mohamed Sayed \\ Gulf Health Council \\ Ali Alwadey \\ Ministry of Health \\ Ejlal F. AlAlawi \\ Ministry of Health \\ Kholoud Almutawaa \\ Ministry of Public Health \\ Amal HJ Hussain \\ Ministry of Health \\ Wedad Al-Maidoor \\ Ministry of Health \\ Yahya M. Al-Farsi \\ Sultan Qaboos University
}

Research Article

Keywords: Cigarette tax, excise tax reform, GCC countries, public health policy

Posted Date: November 1st, 2021

DOI: https://doi.org/10.21203/rs.3.rs-964904/v1

License: (c) (i) This work is licensed under a Creative Commons Attribution 4.0 International License. Read Full License

Version of Record: A version of this preprint was published at BMC Public Health on April 13th, 2022. See the published version at https://doi.org/10.1186/s12889-022-13190-0. 


\section{Abstract \\ Background}

The Gulf Cooperation Council (GCC) countries relied, until recently, solely on import duties for tobacco products. The agreement for the introduction of an excise and value added tax (VAT) in 2016 and 2017, respectively, in most GCC countries, was a major breakthrough for public health. There is, however, ample room for improvement.

\section{Methods}

The study examines the outcomes of tax reforms, for both public health and public finances, based on the World Health Organization (WHO) recommendations and best practices worldwide. Tax simulations were performed using the WHO TaXSiM model. The study is based on data from Saudi Arabia, the only GCC country for which sufficient data existed.

\section{Results}

We recommend a stepwise tax reform, which involves increasing the current ad valorem excise tax rate, phasing out import duties keeping total tax share constant and introducing a minimum excise, and finally switching to a revenue-neutral specific excise. If implemented, cigarette tax reform simulations show that the recommended reforms would lead to a higher than $50 \%$ increase in cigarette prices, $16 \%$ reduction in cigarette sales and almost $50 \%$ increase in total cigarette tax revenue. A significant number of cigarette-related deaths would be averted.

\section{Conclusions}

The recommended tax reforms are expected to lead to significant improvements in both public health and tobacco tax revenues. Our results provide useful insights that are of relevance to the whole GGC region. The effectiveness of the reforms, however, requires a strong tax and customs administration, including the establishment of a good database to monitor and advance public health.

\section{Background}

Design and implementation of tobacco taxation is the most efficient and cost-effective measure to control tobacco consumption [1, 2]. Excise taxation helps improve public health and reduce tobacco-related health expenditure whilst, simultaneously, generating considerable tax revenue [3]. Total cost of smoking and second-hand smoke is estimated to amount to $1.04 \%$ of total gross domestic product (GDP) in the Gulf Cooperation Council (GCC) countries [4].

Before the introduction of excises, the GCC countries relied solely on import duties, putting both revenues and public health at risk due to the pressure of an increasing number of free trade agreements. Minimum import duty was increased, in 2016, between $50-100 \%$ of the cost, insurance and freight (CIF), or equivalent to US \$39 to \$52 per 1000 cigarettes, whichever was higher, and not exceeding the World Trade Organization bound rates. Kuwait was, and still remains, the only GCC country which did not double the minimum import duty on tobacco products [5].

In 2016, the GCC countries collectively agreed to implement a harmonized excise tax at the rate of $100 \%$ of (excise-exclusive) retail price on all tobacco products [6]. The excise was first introduced in Saudi Arabia in June 2017, followed by the UAE and Bahrain in October and December 2017, respectively. In January 2019, the tax was implemented in Qatar, and 5 months later in Oman. Implementation of excise in Kuwait was deferred to the 2020-21 fiscal year. In 2017, GCC countries have also agreed on imposing a value added tax (VAT) on all goods and services [7]. Saudi Arabia and the UAE implemented VAT in January 2018 and Bahrain in January 2019. There are ongoing preparations for VAT implementation in Qatar and Oman in $2021[8,9]$, while Kuwait has not as yet set a date for VAT implementation.

As a consequence of the tax reform, retail volume sales of cigarettes at the GCC level, whilst steadily increasing until 2016, decreased sharply in 2017, according to Euromonitor [10]. This is mainly due to a decrease in retail volume in Saudi Arabia, as it represents $64 \%$ of the GCC retail volume and was the first country to introduce tobacco excises. The UAE market also contributed to this reduction but to a lesser degree [10]. Oxford Economics estimated that cigarette tax revenue across Kuwait, Oman, Saudi Arabia and United Arab Emirates increased by $66.7 \%$ in 2017 relative to the previous year [11]. This increase seems to be entirely due to the introduction of excise taxation, since legal sales decreased.

In all GCC countries cigarettes became less affordable since 2008, with an increase in affordability index in the range of $7.8 \%$ in Qatar to $12.1 \%$ in Saudi Arabia (Table 1). The price dispersion index ranges from 21.8\% in Saudi Arabia to $40 \%$ in Bahrain and UAE (Table 1). This means that the price of the most expensive brand is 4.6 to 2.5 times higher than the price of the cheapest one. As the proportion increases, the gap between cheapest and most expensive brand decreases and, thus, the opportunities to switch to cheaper brands are fewer [12].

In 2018, the sum of excise and import duty as a percentage of final price (all taxes inclusive) of the most sold brand was lower than $75 \%$, which is recommended by the World Health Organization (WHO) $[3,13]$. Specifically, in Bahrain, Saudi Arabia and the UAE, which implemented an excise tax in 
2018 , the share of total tax in final price was $64.5 \%, 63.3 \%$ and $68.8 \%$, respectively. For the remaining countries, where only import duties were implemented, the duty share was extremely low: $21.2 \%$ in Kuwait, $25 \%$ in Oman and $40 \%$ in Qatar. Low tax shares have hardly any effect on consumption and do not exploit the full potential for revenue raising.

The GCC agreement for the introduction of an excise tax and VAT in 2016 and 2017, respectively, was a step in the right direction. Opportunities for improvement, however, still exist. Our aim here is to examine a three-step cigarette tax reform, based on the WHO recommendations as well as best practices followed by countries that adopted successful tobacco tax policies [13,14], and estimate its impact on consumption, prevalence, tobaccorelated deaths and tax revenue.

Table 1

Affordability Index and Price Dispersion Index, 2018

\begin{tabular}{|c|c|c|c|c|c|c|c|}
\hline & & Bahrain & Kuwait & Oman & Qatar & SA & UAE \\
\hline \multirow[t]{4}{*}{ Affordability } & Affordability Index & $2.00 \%$ & $0.88 \%$ & $1.63 \%$ & $0.41 \%$ & $3.16 \%$ & $1.31 \%$ \\
\hline & Trend growth rate in affordability & $10.56 \%$ & $8.58 \%$ & $8.62 \%$ & $7.75 \%$ & $12.12 \%$ & $9.70 \%$ \\
\hline & 2008-2018 & & & & & & \\
\hline & Cigarettes less affordable since 2008 & YES & YES & YES & YES & YES & YES \\
\hline \multirow[t]{5}{*}{ Price Dispersion } & Price of cheapest brand & 2.13 & 0.97 & 1.17 & 0.96 & 1.65 & 2.18 \\
\hline & (pack of 20) USD & & & & & & \\
\hline & Price of most expensive brand (pack of 20) USD & 5.32 & 2.76 & 3.12 & 2.76 & 7.50 & 5.45 \\
\hline & Price dispersion index & $40.0 \%$ & $35.3 \%$ & $37.5 \%$ & $35.0 \%$ & $21.8 \%$ & $40.0 \%$ \\
\hline & Price of most popular brand (Pack of 20) USD & 5.32 & 2.76 & 3.12 & 2.76 & 7.50 & 5.45 \\
\hline
\end{tabular}

Cigarette affordability index is defined as the percentage of per capita GDP required to buy 2000 cigarettes of the most sold brand in a specific year (12). Price dispersion index is defined as the price of the cheapest brand as a percentage of the price of the most expensive one.

\section{Methods}

We considered a three-year reform, starting with straightforward recommendations for immediate action, and then continued with recommendations that might involve lengthy procedures such as amendments in the GCC Treaties $[6,7]$. Keeping in mind that all tobacco products are harmful and should be taxed comparably, we focus on reforms on the rate and structure of the cigarette excise, since data did not exist for other tobacco products. Not much is lost, however, as cigarettes are the most common tobacco product used in GCC countries, although waterpipe tobacco is also used [15, 16].

We recommend the following tax reforms for immediate to medium term action. In the first year, increase the tax rate (excise plus import duty) to be at least $75 \%$ of final retail price (all taxes-inclusive). In the second year, gradually replace import duties, increasing the excise tax rate to compensate, and introduce a minimum excise tax (MET), indexed to inflation rate and income growth. As the global trend is to reduce trade barriers, it is best to replace import duties with domestic taxes to compensate for revenues lost. In this case, as minimum import duties are not in place anymore, a MET per 1000 cigarettes or pack of 20 should be introduced. The MET guarantees a significant increase in price and hence in health benefits. In the third year, the reform would be completed by a gradual switch to specific excise (similarly indexed for inflation and income growth) keeping tax revenue constant. A specific tax is easier to implement and administer as only volume needs to be ascertained. Given quantities are less volatile than prices, revenues from a specific tax are more stable and easier to forecast. Moreover, specific excises lead to lower price competition than ad valorem, leading to higher prices [3]. An ad valorem component, of course, will still apply through VAT.

To test the recommended tax reforms, we performed simulations for Saudi Arabia. All tobacco products are imported since tobacco cultivation and production is banned locally [17]. Cigarette market is characterized by the dominance of premium brands and Marlboro is the most popular brand of the category as well as of the market as a whole [10].

In 2016, when only import duty applied (100\% of CIF value), the estimated (sales-weighted) average tax-inclusive retail sales price (TIRSP) of a pack of 20 was Saudi Rials (SAR) 12.60 (Table 2). Import duty constituted $40 \%$ of the average TIRSP. The amount of import duty remained the same in all examined years as the calculation base is the CIF value, and this was assumed unchanged.

In 2017, excise was introduced and the estimated average TIRSP increased to SAR 25.60 . The excise tax was $50 \%$ of the average TIRSP and share of import duty decreased to $20 \%$. Thus, total tax increased to $70 \%$ of the average TIRSP. Finally, in 2018 , VAT was implemented, increasing the estimated average TIRSP to SAR 26 and total tax (including VAT) to $71.5 \%$ of the average TIRSP. 
Table 2

Estimated cigarette market indicators (averages), in local currency, 2016-2018, Saudi Arabia

\begin{tabular}{|c|c|c|c|}
\hline Cigarette market indicators (Averages) & 2016 & 2017 & 2018 \\
\hline Final price & 12.6 & 25.6 & 26.0 \\
\hline Import duty (SAR) & 5.0 & 5.0 & 5.0 \\
\hline Excise tax (SAR) & 0.0 & 12.8 & 12.4 \\
\hline VAT (SAR) & 0.0 & 0.0 & 1.2 \\
\hline Import duty as \% of final price & 39.7 & 19.5 & 19.2 \\
\hline Excise tax as \% of final price & 0.0 & 50.0 & 47.7 \\
\hline VAT $\%$ of final price & 0.0 & 0.0 & 4.6 \\
\hline Total tax excl. VAT as $\%$ of final price & 39.7 & 69.5 & 66.9 \\
\hline All tax as $\%$ of final price & 39.7 & 69.5 & 71.5 \\
\hline
\end{tabular}

There was an upward trend on both total and legal sales until 2016 [10]. In 2017, both total and legal sales decreased by $19.5 \%$ and $21 \%$, respectively. The difference between total and legal sales is the illegal as well as free trade zone (FTZ) sales, and they were estimated to be $5 \%$ to $7 \%$ of total sales [10]. Oxford Economics, compared to Euromonitor, underestimates the sum of illicit and FTZ sales for the years before the introduction of the excise. In the second quarter of 2018, however, they report a rapid increase of illicit and FTZ sales, reaching $10.7 \%$ of total sales. Regarding cigarette data, let us keep in mind that the main Euromonitor source is the tobacco industry itself and that the Oxford Economics report was funded by the tobacco industry [11].

To estimate the outcomes of the suggested tax policy reforms on cigarette market and tax revenues, we used the WHO TaXSiM model, which requires detailed data on sales, price and taxes per brand [18]. The GCC countries only recently started to collect price data by cigarette brands. Sales by brand, however, are more difficult to find. Hence, prices and sales for most of the cigarette brands (covering just above $90 \%$ of the market) were provided by Euromonitor [10]. Tax information was provided by government. Data on population are available from Saudi Arabia's governmental statistical office [19]. In 2018, cigarette smoking prevalence was reported to be $32.5 \%$ in males and $3.9 \%$ in females, based on a latest study [20].

There are no studies estimating behaviour of either demand or supply side in the GCC tobacco market. Thus, we used demand elasticity values consistent with global evidence [1, 2]. We made conservative assumptions regarding cigarette demand elasticity for three price segments, to estimate a lower bound in consumption change. However, we also performed a sensitivity analysis assuming higher elasticities per price segment. Distribution margins and CIF are assumed to have remained constant; any changes in final retail price are entirely due to changes in tax structure and/or tax rate. The tax is assumed to be fully passed on to consumer prices. Given that data on demand behaviour are not available, it is also initially assumed that consumers do not trade up or down (that is, switch to more or less expensive brands) in response to price increases.

\section{Results}

Starting with the recommendation for immediate application (year 1), we increased the excise tax rate such that total tax (excluding VAT) is equal to $75 \%$ of TIRSP. As excise rate increases, import duty rate is gradually phased out. The average excise per pack increased by $88 \%$ and that resulted in $44 \%$ increase in average price (Table 3 ).

Cigarette sales and industry revenue are expected to fall by $11 \%$ and $10 \%$, respectively. The change in tax revenue is expected to be even more pronounced. Specifically, excise and VAT revenue are expected to increase by $67 \%$ and $28 \%$, respectively. Import duty revenue, however, as expected, will be reduced by $11 \%$. The total tax revenue will increase by $44 \%$. The number of cigarette smokers is expected to decline by $5 \%$ and the overall smoking prevalence will fall by $1 \%$.

Due to the ad valorem nature of the excise tax, changes in key market indicators are expected to be more pronounced for premium brands and smaller for economy brands. The price dispersion index is $38 \%$, since the most expensive brand is estimated at SAR 47.37 and the cheapest brand at SAR 18.05. The price dispersion index is relatively low, creating opportunities for trading down.

On average, excise revenue increases by $67 \%$, but the corresponding increase per price segment is $70 \%$ for premium, $62 \%$ for mid-priced and $54 \%$ for economy brands. Post tax reform, total tax is around $80 \%$ of TIRSP on average, with this share being higher for low-priced cigarettes (around $87 \%$ ) due to the minimum import duty to which they are subjected. 
The next step (year 2 in Table 3) involves replacing import duties with excise duty keeping total tax share (excluding VAT) constant, that is, set excise tax at $75 \%$ of TIRSP and introduce a MET at $70 \%$ of weighted average price (WAP). The introduction of MET (SAR 28) has an impact on both midpriced and economy brands. Excise tax as percentage of TIRSP is $76 \%$ for mid-priced and $87 \%$ for economy brands. Thus, MET has a significant effect especially for economy brands.

This reform would lead to a further $8 \%$ increase in average price, $4 \%$ reduction in sales, $4 \%$ increase in total cigarette tax revenue and, more specifically, $27 \%$ increase in excise revenue and $3 \%$ increase in VAT revenue. Furthermore, it will lead to $2 \%$ reduction in number of smokers with $0.4 \%$ reduction in smoking prevalence.

Finally (year 3 in Table 3), a switch to a revenue-neutral specific tax rate is recommended. The ad valorem rate is replaced by a specific excise such that excise tax revenue remains constant. According to our simulations, this corresponds to a specific excise at SAR 31 . Even when we adopt a tax reform that keeps excise revenue constant, the change in tax structure is estimated to lead to a further $1 \%$ increase in average pack price, $1 \%$ reduction in sales, and $0.3 \%$ reduction in number of smokers with $0.1 \%$ reduction in prevalence. Setting a higher specific rate will lead to further reductions in sales and increases in tax revenue.

Table 3

Simulated tax effects on consumption, revenue and number of smokers in Saudi Arabia

\begin{tabular}{|c|c|c|c|}
\hline & \multicolumn{3}{|c|}{ Model predictions } \\
\hline & Year 1 & Year 2 & Year 3 \\
\hline Average cigarette pack price (SAR) & 38 & 40 & 41 \\
\hline Average total tax per pack & 30 & 33 & 33 \\
\hline Average excise per pack & 23 & 31 & 31 \\
\hline Change in price per pack & $44 \%$ & $8 \%$ & $1 \%$ \\
\hline Change in average excise per pack & $88 \%$ & $33 \%$ & $1 \%$ \\
\hline Import duty as \% of final price & $13 \%$ & - & - \\
\hline Excise tax as \% of final price & $62 \%$ & $76 \%$ & $76 \%$ \\
\hline Total tax as \% of final price & $80 \%$ & $81 \%$ & $81 \%$ \\
\hline \multicolumn{4}{|c|}{ Assume: $e($ premium $)=-0.2 ; e($ mid-price $)=-0.3 ; e($ economy $)=-0.4$} \\
\hline Change in number of smokers & $-5 \%$ & $-2 \%$ & $-0.3 \%$ \\
\hline Change in prevalence & $-1 \%$ & $-0.4 \%$ & $-0.1 \%$ \\
\hline Change in sales & $-11 \%$ & $-4 \%$ & $-1 \%$ \\
\hline Change in excise revenue & $67 \%$ & $27 \%$ & $0 \%$ \\
\hline Change in VAT revenue & $28 \%$ & $3 \%$ & $5 \%$ \\
\hline Change in import duty revenue & $-11 \%$ & - & - \\
\hline Change in total tax revenue & $44 \%$ & $4 \%$ & $0.2 \%$ \\
\hline Change in industry revenue & $-10 \%$ & $-2 \%$ & $-0.3 \%$ \\
\hline
\end{tabular}

Overall, the three-year reform would lead to a higher than $50 \%$ increase in cigarette prices, $16 \%$ reduction in cigarette sales and almost $50 \%$ increase in total cigarette tax revenue. The final total tax share would be $81 \%$ and the excise share $76 \%$ of (all-taxes inclusive) final price.

Assuming an overall price elasticity of demand equal to -0.3 , we also estimated the number of deaths averted. Based on the standard estimate that the elasticity of smoking prevalence accounts for half of the total demand elasticity, that one in two of all regular smokers will die eventually, and that all quitters will survive [21], we estimated that 88,340 deaths related to cigarette smoking would be averted after the first year of the tax reform. This is a $6.6 \%$ reduction in cigarette-related deaths. Assuming a higher demand elasticity, of course, would lead to more deaths averted. For example, at a total demand elasticity equal to -0.4 , cigarette-related deaths would fall by $8.8 \%(117,787$ deaths would be averted) after the first year of the tax reform.

\section{Sensitivity analysis}


Our elasticity assumptions are rather conservative. Increasing cigarette demand elasticity per price segment, the estimated reduction in smoking prevalence is higher. Assuming, for example, a demand elasticity of $-0.3,-0.4$ and -0.5 for premium, medium priced and economy brands respectively (scenario 1 ), smoking prevalence would fall by $1.4 \%$ (- $2.3 \%$ over the period of 3 years). Assuming, a demand elasticity of $-0.4,-0.5$ and -0.6 for premium, medium priced and economy brands respectively (scenario 2$)$, smoking prevalence would fall by $1.8 \%$ (- $2.5 \%$ over the period of 3 years).

Obviously, depending on the elasticity assumptions, there is a trade-off between a higher decrease in sales and hence the number of smokers and prevalence rate, and a lower increase in tax revenue. In scenario 1 and over the 3 -year period, sales would fall by $21 \%$, and excise tax revenue and total tax revenue would increase by $84 \%$ and $40 \%$, respectively. In scenario 2 and over the 3 -year period, sales would fall by $28 \%$, and excise tax revenue and total tax revenue would increase by $75 \%$ and $32 \%$, respectively.

Finally, assuming no trading down, we overestimate the reduction in sales and hence underestimate the increase in tax revenue. When, we allow for some trading down, that is, consumers turning to cheaper brands as prices go up, our results do not change significantly. In the absence of solid data, it is safer not to make any arbitrary assumptions on trading down or up.

\section{Discussion}

The recent introduction of excise taxes by five of the six GCC countries, after five decades of sole reliance on custom duties, was a significant and major reform of the tobacco taxation policy. However, as a fulfilment of the GCC countries obligation under Article 6 of the WHO Framework Convention on Tobacco Control (FCTC) [22], tobacco taxation has to be aligned with the WHO recommendation that tobacco excise taxes account for at least $70 \%$ of the retail prices [3]. Simulations for Saudi Arabia show that a reform to this direction will lead to a significant increase in tax revenues and a reduction in cigarette use. The addition of VAT will contribute further to higher retail prices for cigarette products and higher tax revenues.

Our study proposed a three-step reform which, if implemented, is expected to lead to a reduction between $5 \%$ and $7.3 \%$ in number of smokers, and between $1-1.5 \%$ in smoking prevalence, over a 3-years period. Government revenues are expected to grow by 44 to $48 \%$. The reform will result in a more robust GCC tax system and in line with WHO and FCTC recommendations [3, 22].

The tax base must be defined as clear and as wide as possible for the tax to be more effective in reducing tobacco use and raising revenues. Packs of tobacco products can have a "maximum retail price", stated on an affixed tax stamp, which also indicates excise has been paid in the particular country. This will facilitate identifying products illegally brought into the GCC countries. Saudi Arabia and UAE have started to implement such a tracking and tracing system in early 2019 and others are likely to follow similar procedures [23, 24].

Weak tax administration may lead to inefficiencies in tax collection and compliance when that tax is ad valorem, increasing the risk of tax avoidance and tax evasion [2]. This potential problem is one of the reasons, but not the main one, we recommend to gradually switch to specific excises and introduce a minimum excise floor $[3,14]$. The European Union experience confirms that, even though price differentials still exist among member states, setting a minimum on the share of taxes in final price and a minimum excise tax, a certain level of approximation has been reached contributing to a declining trend in tobacco consumption and a stable trend in tax revenues [25].

A uniform specific tax is simple and raises price relatively more than an equivalent amount of ad valorem tax. Set at a high rate, specific taxes tend to reduce price dispersion and thus downward trading by the most vulnerable in society. In addition, specific taxes subdue manufacturers' incentive to market low-priced products. It is important specific excises, including MET, be adjusted for inflation and income growth regularly, to ensure cigarettes do not become more affordable as income and inflation rise.

Governments should abolish duty free sales of tobacco products and cigarettes sold in packs of 10 or individual sticks, and small packets of other tobacco products such as waterpipe tobacco, as they accommodate affordability. Abolishing them will help preventing the youth and children from starting smoking. Manufacturers may be granted a short grace period to sell existing stock.

The qualitative results of our analysis are expected to apply to all GCC countries since they share similar market characteristics and harmonized import duties and taxes. Cigarettes is the most used tobacco product in all countries, with premium brands dominating the market and Marlboro being the most popular brand [10]. Although our analysis is based on cigarettes, we believe that the qualitative results can be generalized to all tobacco products in the GCC bloc. Given our proposals to increase taxes on all tobacco products, GCC governments should be vigilant of the repeated tobacco industry's lobbying tactics of using the issue of smuggling in hindering implementation of tax reforms [26]. A recent publication on the interferences of the tobacco industry showed how industry representatives lobbied individual countries in the GCC to veto tax increments and defeat consensus on agreed resolutions of the Health Ministers' Council [27].

\section{Limitations of the study}

Our study has a few limitations. First, with the exception of Saudi Arabia, GCC countries did not have data on consumption on tobacco products by brands and types. Moreover, any available data related only to cigarettes and not the full range of tobacco products. However, we believe that our analysis applies equally to other tobacco products. Second, data on one country, Saudi Arabia, are used to generalize results of tax reforms to the other GCC states, had they applied the same tax structure and rates. Although, the quantitatively results may differ, their qualitative nature most certainly will hold. 


\section{Conclusions}

Our stepwise tax reform, involving changes in both tax rates and tax structure as well as phasing out of import duties, is expected to lead to significant improvements in both public health and tobacco tax revenues. The results provide useful insights that are of relevance to the whole GGC region. The effectiveness of the reforms, however, requires a strong tax and customs administration, including the establishment of a good database to monitor and advance public health.

Tax reforms must be supported by strengthened tax and customs administration, to ensure efficient and effective tax introduction and implementation. For a successful tax reform, data collection and sharing are paramount. Data collection is very important for understanding and addressing tobacco control. The GCC countries face great challenges in data collection and, hence, data analysis. Building a good administrative database, which can be regularly updated, will enable researchers to estimate accurate tobacco market features for each individual country and assess the impact of proposed tobacco policy reforms on both public health and public revenues. Policy makers can, then, make informed policy decisions. Political commitment facilitates coordination of all relevant agencies and contains resistance of vested interests. Hence, it accelerates reforms. Moreover, promoting national ownership of reform in collaboration with the WHO enables effective communication with shareholders and helps overcome their resistance, making clear what the potential benefits from the reforms, as well as the costs of maintaining the status quo, are.

\section{Abbreviations}

CIF: Cost, Insurance and Freight

FTZ: Free Trade Zone

GCC: Gulf Cooperation Council

GDP: Gross Domestic Product

MET: Minimum Excise Tax

SA: Saudi Arabia

TIRSP: Tax-Inclusive Retail Sales Price

UAE: United Arab Emirates

VAT: Value Added Tax

WAP: Weighted Average Price

WHO: World Health Organization

\section{Declarations}

\section{Ethics approval and consent to participate}

No required

\section{Consent for publication}

Not required

\section{Availability of data and materials}

Data are available on reasonable request. All data relevant to the study are included in the article. Further data would be available on request to Gulf Health Council. Data include details of study protocols, statistical analysis plans and extensive background statistical analysis conducted.

\section{Competing interests}

All authors declare that they have no conflicts of interest.

\section{Funding}

This work is part of the research project 'Tobacco Economics in the GCC countries', funded by the Gulf Health Council, the executive arm of the Council of Ministers of Health at GCC countries.

\section{Authors' contributions}


SD, KK, and MS formulated the study concept. JAA, contributed to collection and acquisition of data. JAA, SD, KK, and YF contributed to literature review, and write-up of the manuscript. SD and KK conceptualized the methods and contributed to reviewing results and the write-up of the manuscript. SD, JAA, and KK conceptualized the costs estimate techniques, reviewed the results and contributed to the write-up. MS, JAA, AA, EA, KK, AH, and WM contributed to both design and data collection in the field and the write-up. JAA, SD, KK, and YF revised the scientific background of the study and contributed to the literature review and write-up of the manuscript, especially the Discussion section. All authors read and approved the final manuscript.

\section{Acknowledgements}

The authors acknowledge the support of relevant colleagues and officials at Ministries of Health at GCC for facilitating collection of data.

\section{References}

1. International Agency for Research on Cancer. IARC Handbooks of Cancer Prevention, Tobacco Control, Volume 14: Effectiveness of Tax and Price Policies for Tobacco Control. Lyon, France: International Agency for Research on Cancer; 2011.

2. U.S. National Cancer Institute and World Health Organization. The Economics of Tobacco and Tobacco Control. National Cancer Institute Tobacco Control Monograph 21. NIH Publication No. 16-CA-8029A. Bethesda, MD: U.S. Department of Health and Human Services, National Institutes of Health, National Cancer Institute; and Geneva, CH: World Health Organization; 2016.

3. WHO Technical manual on tobacco tax administration. Geneva: World Health Organization; 2010 (https://www.who.int/tobacco/publications/tax_administration/en/, accessed 7 October 2019).

4. Koronaiou K, Al-Lawati J, Sayed M, Alwadey A, Alalawi E, Almutawaa K et al. The Economic Cost of Smoking and Secondhand Smoke Exposure in the Gulf Cooperation Council Countries. Tob Control J 2020. http://dx.doi.org/10.1136/tobaccocontrol-2020-055715.

5. General Secretariat of the Gulf Cooperation Council, Gulf Customs Union, Unified Customs Tariff for GCC states 2017. Oman: GCC Statistical Center (https://gccstat.org/ar/statistic/standards/gcc-cet-2017, accessed 19 October 2019).

6. The Unified Selective Tax Agreement for the Arab Gulf Cooperation Council Countries. Riyadh: Secretariat General of the Gulf Cooperation Council; 2016 (in Arabic)_(https://www.mof.gov.ae/ar/lawsAndPolitics/govLaws/Documents/Excise\%20Final\%2030\%20Nov\%202016(updated).pdf, accessed 19 October 2019).

7. Common VAT Agreement of the States of the Gulf Cooperation Council. Riyadh: Secretariat General of the Gulf Cooperation Council; 2017 (in Arabic) (https://www.mof.gov.ae/en/lawsandpolitics/govlaws/pages/commonvatagreement.aspx, accessed 19 October 2019).

8. Asquith R. Qatar VAT delayed till 2021. Avalara VATlive. 2019 (https://www.avalara.com/vatlive/en/vat-news/qatar--no-vat-till-2021-or-later.html, accessed 14 January 2020).

9. Hariharan A, Penning R, Lekhak A. Tax flash: VAT to be implemented in Oman. KPMG. 2020 (https://home.kpmg/om/en/home/insights/2020/01/oman-tax-alert-vat-to-be-implemented-in-oman.html, accessed 29 January 2020).

10. Cigarettes in GCC countries. London: Euromonitor International; 2018 (https://www.euromonitor.com/cigarettes, accessed 7 January 2019 ).

11. GCC Illicit Tobacco Indicator 2017. Oxford: Oxford Economics; 2018 (https://www.oxfordeconomics.com/recent-releases/cc171505-2abe-4474845e-05d8003ba678, accessed 28 March 2019).

12. Appendix VII. Table 9.6. WHO Report on the Global Tobacco Epidemic, 2019. Geneva: World Health Organization; 2019 (https://www.who.int/tobacco/global_report/en/, accessed 20 September 2019).

13. WHO Report on the Global Tobacco Epidemic, 2019. Geneva: World Health Organization; 2019 (https://www.who.int/tobacco/global_report/en/, accessed 20 September 2019).

14. Economics of Tobacco Taxation Toolkit. WBG Global Tobacco Control Program. Washington, D.C.: World Bank Group; 2018 (http://documents.worldbank.org/curated/en/238861522243274209/Economics-of-Tobacco-Taxation-Toolkit, accessed 15 March 2019 ).

15. World Health Organization FCTC Implementation Database. WHO Framework Convention on Tobacco Control. Geneva: World Health Organization (https://untobaccocontrol.org/impldb/, accessed 8 April 2019).

16. Al-Mulla AM, Helmy SA, Al-Lawati J, Nasser SA, Rahman SAA, Almutawa A, et al. Prevalence of tobacco use among students aged 13-15 years in Health Ministers' Council/Gulf Cooperation Council Member States, 2001-2004. J Sch Health. 2008;78(6):337-43.

17. Executive Regulations for Anti-smoking Law issued by the Royal Decree No. (M /56) dated 28/7/1436 AH. Ministry of Health, Riyadh (in Arabic) (https://www.moh.gov.sa/Ministry/Rules/Documents/22.pdf, accessed 7 March 2019).

18. WHO Tobacco Tax Simulation Model (WHO TaxSim). Geneva: World Health Organization (https://www.who.int/tobacco/economics/taxsim/en/, accessed 10 January 2019).

19. Statistical Yearbook of 2017. Saudi Arabia: General Authority for Statistics; 2018 (https://www.stats.gov.sa/en/258, accessed 12 March 2019).

20. Algabbani A, Almubark R, Althumiri N, Alqahtani A, BinDhim N. The Prevalence of Cigarette Smoking in Saudi Arabia in 2018. Food Drug Regul Sci J 2018;1(1):1. doi: 10.32868/rsj.v1i1.22

21. Doll R, Peto R, Wheatley K, Gray R, Sutherland I. Mortality in relation to smoking: 40 years' observations on male British doctors. BMJ. 1994; 309(6959):901-11. doi: 10.1136/bmj.309.6959.901. 
22. Sixth Session of the Conference of the Parties to the WHO Framework Convention on Tobacco Control. FCTC/COP6(5): Guidelines for implementation of Article 6 of the WHO FCTC (Price and tax measures to reduce the demand for tobacco); 2014

(https://apps.who.int/gb/fctc/PDF/cop6/FCTC_COP6(5)-en.pdf, accessed 14 January 2019).

23. De La Rue awarded digital tax stamp solution contract by The Kingdom of Saudi Arabia. United Kingdom: De La Rue; 2019 (https://www.delarue.com/media-center/de-la-rue-awarded-digital-tax-stamp-solution-contract-by-the-kingdom-of-saudi-arabia, accessed 23 November 2019).

24. UAE track and trace service for cigarettes delivered by De La Rue reaches major milestone. United Kingdom: De La Rue; 2019 (https://www.delarue.com/media-center/uae-track-and-trace-service-for-cigarettes-delivered-by-de-la-rue-reaches-major-milestone, accessed 23 November 2019).

25. Excise Duty Tables Part III - Manufactured Tobacco. Brussels: European Commission; 2019 (https://ec.europa.eu/taxation_customs/sites/taxation/files/resources/documents/taxation/excise_duties/tobacco_products/rates/excise_dutiespart_iii_tobacco_en.pdf, accessed 10 April 2019).

26. Allen R. Oman Working Group, Infotab Facsimile Transmission. (https://www.industrydocuments.ucsf.edu/tobacco/docs/\#id=rxpy0198, accessed 23 Jun 2020).

27. Al-Lawati JA, Bialous SA. Tactics of the tobacco industry in an Arab nation: a review of tobacco documents in Oman. Tob Control. 2021. doi: 10.1136/tobaccocontrol-2021-056623 